\title{
Terapia Ocupacional eco-social: hacia una ecología ocupacional ${ }^{1}$
}

\author{
Salvador Simó Algado \\ Doctor en Educación Inclusiva, Terapeuta Ocupacional, \\ Facultad de Ciencias de la Salud y del Bienestar, Universitat de Vic, España
}

\begin{abstract}
Resumen: Si bien los terapeutas nos postulamos como expertos en la ocupación humana hemos desatendido aspectos claves del medio, como son tanto los condicionantes sociopolíticos como los ecológicos. La actual crisis ecológica no puede pasar desapercibida para los terapeutas ocupacionales, ya que la ocupación humana es el diálogo entre la persona (grupo o comunidad) y el medio. Este artículo reflexiona sobre el impacto de los factores ecológicos en la salud y el bienestar humanos, así como en el papel de la terapia ocupacional ante esta crisis ecológica, una crisis que no podemos separar de la crisis social. Concluye que la ocupación humana ha sido un factor clave en la génesis del problema y debe serlo en su solución. Plantea el concepto de ecología ocupacional para el desarrollo de una terapia ocupacional eco-social basada en la construcción de comunidades inclusivas y sostenibles, abriendo un campo de nuevas posibilidades para nuestra profesión.
\end{abstract}

Palabras clave: Ecología, Terapia Ocupacional, Medio Ambiente, Comunidad, Desarrollo Sostenible.

\section{Terapia Ocupacional ecossocial: por uma ecologia ocupacional}

Resumo: A postulação dos terapeutas ocupacionais como peritos em ocupação humana tem negligenciado aspectos-chave do ambiente, sendo que se faz necessária a abordagem tanto dos condicionantes estruturais e sociopolíticos como dos ecológicos. A atual crise ecológica não pode passar despercebida para os terapeutas ocupacionais, uma vez que a ocupação humana pode ser entendida como o diálogo entre a pessoa (grupo ou comunidade) e seu meio. Este artigo reflete sobre o impacto dos fatores ecológicos na saúde e bem-estar humanos, bem como sobre o papel da terapia ocupacional frente a esta crise ecológica, que não pode ser separada da crise social. Conclui-se que a ocupação humana é um fator-chave na gênese do problema e deve ser também sua solução. Evidencia-se o conceito de ecologia ocupacional para o desenvolvimento de uma terapia ocupacional ecossocial baseada na construção de comunidades inclusivas e sustentáveis, abrindo um campo de novas possibilidades para nossa profissão.

Palavras-chave: Ecologia, Terapia Ocupacional, Meio Ambiente, Comunidade, Desenvolvimento Sustentável.

\section{Eco-social Occupational Therapy: on the way to occupational ecology}

\begin{abstract}
Although we proclaim ourselves as therapists specialized in human occupation, we have not been able to deal with key environmental issues such as the sociopolitical and ecological conditioning aspects. Nowadays, the ecological crisis cannot be overlooked by occupational therapists, once the human occupation is the dialogue between the person (group or community) and its environment. This study reflects upon the impact of ecological factors on human health and wellbeing, as well as on the role that occupational therapy plays in this ecological crisis, which cannot be separated from the social crisis. The conclusion is that human occupation has been a key
\end{abstract}

Autor para correspondência: Salvador Simó Algado, Universitat de Vic. Sagrada Familia 7, 08500 Vic, España,

e-mail: salvador.simo@uvic.cat

Recebido: 10/2/2012; Aceite final:16/3/2012. 
issue since the beginning of this problem and must seriously contribute to its solution. The concept of occupational ecology is reaffirmed in the development of an eco-social occupational therapy, based on the building of inclusive and sustainable communities, opening a field of new possibilities for our profession.

Keywords: Ecology, Occupational Therapy, Environment, Community, Sustainable Development.

\section{Habitantes en un mundo esférico, enfermo y contaminado}

Nada de lo humano me es ajeno. Terencio

En la Prehistoria las sociedades arcaicas de cazadores y recolectores se extendieron por las tierras. Durante decenas de miles de años fueron extrañas unas a las otras por la distancia, el lenguaje, los ritos y las creencias. La Historia nace hace miles de años en Mesopotamia y en los valles del Nilo, del Indo y de Huang Po. La Historia es el crecimiento y la lucha a muerte entre los Estados. Es la construcción de grandes civilizaciones que se creen eternas siendo todas mortales. En el siglo XV empieza la Era planetaria, dando inicio a la Modernidad. La conquista de América vino acompañada de saber que habitamos un planeta esférico, el primer globo terráqueo aparece en Núremberg en 1492 (MORIN, 1993). Kant (1946) entendió en el siglo XVIII que este planeta esférico no permite una dispersión infinita, por lo que sus habitantes están obligados a entenderse y colaborar, proponiendo la creación de una República planetaria. Somos habitantes de un mundo esférico con un destino común.

Sin embargo en occidente uno de los tópoi, o creencia fuerte, es la independencia del ser humano, lo que se traduce en un proceso de severa individualización (BECK; BECK-GERNSHEIM, 2003) que fragmenta todo lo comunitario. Sesgadamente la cosmovisión occidental entiende al hombre como un ser aislado que está por encima del medio natural. El hombre occidental se separó de Oriente, del Salvaje y de la Naturaleza (SANTOS, 2005). Oriente simboliza el espacio de la alteralidad. El Salvaje, representado por los pueblos indígenas y del Sur, simboliza la inferioridad. Y finalmente la Naturaleza, que simboliza el espacio de exterioridad, convertido en mero recurso económico. En el caso de la Naturaleza esta percepción escindida se materializa en el culto irracional e idólatra al desarrollo tecnológico, en el marco de un sistema neoliberal donde el hombre está al servicio de la economía. Pero esta economía excluye de sus cálculos la ley de la entropía, la no reversibilidad de las transformaciones de la energía y de la materia. Los residuos y la contaminación resultantes, a pesar de ser productos de la actividad económica no son tenidas en cuenta (LATOUCHE, 2009). Una economía basada en la idea demente de la posibilidad de un crecimiento ilimitado un en mundo con recursos limitados. La consecuencia es la grave crisis ecológica que confronta la Humanidad.

Tampoco podemos obviar el sufrimiento social provocado en forma de depresiones, suicidios, adicciones, etc. relacionados con la precariedad laboral y la exclusión de grandes sectores de la población de la actividad productiva, convertidos en residuos humanos (BAUMAN, 2005). Este sufrimiento no es tenido en cuenta en el balance de las empresas y simplemente se psiquiatriza el malestar social (RENDUELES, 2006). Se convierte en un diagnóstico mental del que se responsabiliza a las víctimas, consideradas como perdedoras y a las que se medicaliza, sin abordar los orígenes sociales del malestar, basados entre otros en la negación del acceso a un trabajo digno y en la explotación laboral que convierten al ser humano, al bios politkos, en un animal laborans. El resultado es la emergencia de grandes sufrimientos humanos, cuyo centro es la violación de los derechos humanos o la ausencia de ellos (GUAJARDO, 2011).

Otra consecuencia es un planeta enfermo. Según Boff (2000) entre 1500 y 1850 fue eliminada una especie cada diez ańos. Entre 1850 y 1950 una especie por año. En el año 2000 desaparecía una especie por hora. El proceso de muerte se acelera cada vez más. Entre 1975 y 2000 desaparecieron el 20\% de todas las especies vivas. Los principales problemas globales que afectan al medio son: la lluvia ácida, el calentamiento de la atmósfera, la destrucción de la capa de ozono, la deforestación, la desertización y la superpoblación.

La lluvia ácida es el resultado del desenfrenado proceso de industrialización. La emisión de bióxido de azufre, en combinación con el óxido de nitrógeno 
y con el agua de la lluvia, se transforma en partículas ácidas que se depositan en la vegetación, en los ríos, en los lagos, produciendo la contaminación de los alimentos y enfermedades. Cerca de 650 millones de personas están expuestas diariamente a tasas insalubres de óxido de azufre (BOFF, 2000).

El efecto estufa resulta de la quema de combustibles fósiles (petróleo y carbón) que desprenden dióxido de carbono y de otros gases como el metano. Sus responsables son la industria, la producción de energía eléctrica, los sistemas de climatización, la ganadería y el transporte (SOLANAS, 2010). Estos gases, asociados a la deforestación calientan la atmósfera. En el último siglo la temperatura aumentó en $0.6^{\circ} \mathrm{C}$. Para los próximos cien años se espera un crecimiento de 1.5 a $5.5^{\circ} \mathrm{C}$, lo que provocaría desastres descomunales debido a la sequía, disminución de lluvias y al deshielo de los casquetes polares. Si el océano crece un metro inundará el $10 \%$ de Bangla Desh, desplazando a 8 millones de habitantes (BOFF, 2000).

La emisión de compuestos químicos industriales (llamados clorofluocarbonos, CFC) provoca el agujero de la capa de ozono, estrato atmosférico de 30 a 50 kilómetros de la superficie de la Tierra. Su destrucción haría desaparecer la protección de la vida de las radiaciones ultravioletas, causantes de cáncer de piel y del debilitamiento del sistema inmunitario.

A partir de 1950 se perdió una quinta parte de la superficie cultivable y de los bosques tropicales. Cada año desaparecen 25 millones de toneladas de humus por causa de la, erosión de la salinización y de la desertización, lo que equivale a un área de los países del Caribe (excepto Cuba). Los bosques del mundo se están talando a un ritmo de 20 millones de hectáreas por año (BOFF, 2000). La tala de los bosques naturales para su transformación en monocultivos de agricultura industrial genera ingresos y crecimiento, Brasil quizás es su mayor paradigma. Pero lo hace a costa de robar al bosque su biodiversidad y su capacidad para conservar suelos y agua, medicinas, alimento, y de servir de protección contra las inundaciones y sequías. La ilusión de desarrollo encubre un robo a la naturaleza y a los pobres, la creación de escasez se esconde tras la máscara de crecimiento (SHIVA, 2003).

La población mundial está creciendo de un modo alarmante. En 1950 éramos 2.500 millones. En el año 2000 éramos 6.400 millones. En 2011 llegamos a los 7.000 millones. La humanidad necesitó de 10.000 generaciones para llegar a los 2.000 millones y apenas una sola generación para pasar de los 2.000 millones a los 5.500 millones. Si sigue este ritmo en la próxima generación seremos 11.000 millones, ¿el ecosistema Tierra es capaz de absorber a tantos habitantes? La tasa de crecimiento del mal llamado Tercer Mundo es del orden del $4 \%$ anual y la de la alimentación es del $1.3 \%$. Dos tercios de la población mundial son pobres y 60 millones de personas mueren de hambre y enfermedades derivadas de ella, 20 millones son niños (BOFF, 2000).

La contaminación es un problema global con múltiples manifestaciones. Acompaña al ser humano desde que introdujo el fuego para calentarse en las cuevas. La historia de la Humanidad es un proceso lento donde se producen saltos cualitativos importantes. El primero se debió a la introducción de la agricultura. El siguiente fue la Revolución industrial, entre los siglos XVIII y XIX. La Revolución química y del transporte están vinculadas a la contaminación de las ciudades durante los siglos XX y XXI. La materia contaminante más antigua son los residuos humanos. El 40\% de los habitantes del mundo carece de un inodoro, las enfermedades asociadas se cobran 2 millones de vidas. La contaminación por metales es un grave problema. Sirva de ejemplo Cracovia, donde en los ańos 80 caían anualmente 170 toneladas de plomo, 470 de zinc y 18 de hierro. Cada ańo 2 millones de personas mueren debido a la contaminación del aire, el conocido smog, provocada por el tráfico, las calefacciones y las industrias. El agua también es un importante foco de contaminación, unos 1.000 millones de personas no tienen acceso al agua y más de 2.000 millones carecen de redes de saneamiento. En la ciudad rusa de Dzerzhininsky, donde se fabricaron armas químicas, alrededor de 300.000 toneladas de residuos fueron desechadas ente 1930 y 1998, afectando a los acuíferos, con más de 150 productos químicos. En la zona la esperanza de vida es de 42 años para hombres y 47 para mujeres. En 2003 la tasa de mortalidad superó un 260\% la de natalidad. En cuanto a la contaminación química sabemos que hoy nuestros organismos portan entre 300 y 500 sustancias químicas que no tenían las personas hace 80 años. Esta contaminación química manifiesta su toxicidad de forma retardada, con enfermedades cardiorespiratorias, endocrinas y cáncer. El 80\% de los cánceres son de etiología ambiental. Lo más grave es que desconocemos a ciencia cierta sus efectos, en especial cuando interactúan diversos componentes de forma simultánea. Otros tipos de contaminación son la auditiva, la lumínica y la electromagnética. Mientras la Organización Mundial de la Salud establece en 50 decibelios el límite tolerable de ruido, el tráfico de las ciudades llega a 
los 70 decibelios. Si bien sus efectos se consideran normales y hay mucha permisividad social, un estudio de la Organización Mundial de la Salud establece un claro riesgo de tumor cerebral para las personas que abusan del móvil. La contaminación nuclear es la más mortífera. Chernóbil (1986) y Fukushima (Japón, 2011) son los episodios más celebres, junto a los desastres de Three Mile Island (USA, 1979), Windscale (Reino Unido, 1957) y Mayak (Rusia, 1957). De los 10 mayores productores de uranio, siete se encuentran en países donde las normas de seguridad industrial no se respetan escrupulosamente: Kazajstán, Rusia, Níger, Namibia, Uzbekistán, Ucrania y China (SOLANAS, 2010).

La Tierra es como un corazón gravemente lesionado, el resto de organismos vitales se verán afectados. La sostenibilidad del planeta, tejida en millones de años de trabajo cósmico puede verse desbaratada (BOFF, 2001). La gravedad de la situación nos tiene que llevar a un compromiso con el planeta, cuestionando nuestros estilos de vida y las ocupaciones con las que los entretejemos. De lo contrario daremos vida al cuadro de Ensor (1891), Cadáveres disputándose un ahorcado, donde Gaia será ese ahorcado que se disputan dos cadáveres, cuyo final inevitablemente compartiremos los seres humanos. Por la puerta del cuadro asoman personajes enmascarados, bien pueden simbolizar las próximas generaciones que esperan su turno para vivir.

\section{E1 medio ambiente y la conciencia ecología}

\section{Hay que recomponer el todo. Marcel Maus}

Podemos definir el medio ambiente (natural) como el conjunto de seres naturales bióticos y abióticos que rodean a un organismo, población o comunidad humana y del que como sistemas abiertos dependen para su propia supervivencia (GARCÍA, 2004). El término ecología fue acuñado por el biólogo alemán Ernst Kaeckel, está formado por dos palabras griegas: oikos que significa casa y logos que significa estudio. La ecología es el estudio de la interdependencia y de la interacción entre los seres vivos y su medio ambiente. Boff (2000) nos da una visión más holística al definir la ecología como relación, inter-acción y diálogo de todas las cosas existentes entre sí y con todo lo que existe. No tiene sólo que ver con la naturaleza sino principalmente con la sociedad y la cultura. Nada existe fuera de esta relación. Ésta es una definición integradora, que relaciona naturaleza, sociedad y cultura, no en vano Boff afirma que la pobreza es el principal problema medioambiental.

En occidente, los antecedentes del desarrollo de una conciencia ecológica los encontramos a principios de los 60 en científicos como Bertrand Russell (1962, p. 24):

¿Es posible que lo sociedad científica siga existiendo o nos tiene que llevar a la destrucción? No sé los horrores que nos aguardan, pero a menos que se haga algo radical, el hombre de la edad científica está sentenciado.

En 1962 Carson (2010) publica La primavera silenciosa. El artista Hundertwasser (RAND, 2007), a principios de los 70 desarrolló acciones de arte urbano como Árbol Inquilino. El Informe del Club de Roma sobre los límites del crecimiento (MEADOWS, 1972) y la Conferencia de Estocolmo sobre Desarrollo y Medio Ambiente, fueron momentos destacados. Empezamos entonces a comprender el impacto de las acciones humanas en el medioambiente, que es el resultado de la población (número de individuos), la riqueza (medida de recursos consumidos) y la tecnología (de acuerdo con un índice de destrucción medioambiental causada por los procesos productivos) (EHRLICH; EHRLICH, 1993). Esta consciencia está arraigada de forma milenaria en la mayoría de las culturas no occidentales. En los años 80 Lovelock (1985) con su hipótesis Gaia nos hizo pensar en la tierra como en un ser vivo. En 1983 se organizó desde Naciones Unidas (NU) la Comisión Mundial sobre el Medio Ambiente y el Desarrollo, presidida por Brundtland, donde se acuñó el famoso concepto de desarrollo sostenible: aquel desarrollo que asegura las necesidades presentes sin comprometer las de las generaciones futuras para satisfacer las propias (COMISSÃO..., 1998). Este concepto ha sido criticado por su ambigüedad y por no cuestionar la propia idea de desarrollo, que va ligada a la de crecimiento, en su lugar se ha propuesto el concepto de sostenibilidad (a secas), que entiende que el éxito de la economía humana depende de no agotar las fuentes de recursos y no saturar los vertederos. Asimismo es consciente de que el crecimiento de las economías industriales se ha basado en buena medida en la sobreexplotación de las funciones naturales útiles. A estas iniciativas pioneras les seguirían la Cumbre de la Tierra de Río (1992) o de Johannesburgo (2002) y documentos como la Carta de la Tierra o la Agenda 21, que contempla medidas de reparación del medio. Recientemente hemos asistido al fracaso de la Cumbre de Durban sobre el Cambio climático (2011). 
La relación entre sociedad y naturaleza es la de un sistema abierto cuyo medio ambiente es un sistema cerrado (impuesto por los límites del planeta Tierra), esto nos confronta con el principio de límite de los recursos naturales. Además, la complejidad tanto de la sociedad como de la naturaleza nos confrontan con el principio de indeterminación, que resulta de dos sistemas complejos auto-organizadores que se relacionan. No podemos controlar esta interacción. Hemos vivido sumidos en la ilusión de que los avances tecnológicos nos eximían de nuestra dependencia de la naturaleza. Nuestro antropocentrismo hace que lo interpretemos todo en términos de los valores humanos, desde un exencionalismo, el pensar que las leyes de la física y la biología no condicionan las organizaciones humanas (GARCÍA, 2004).

Un concepto clave es el de huella ecológica (LATOUCHE, 2009), que es la superficie de la tierra biológicamente productiva que se precisa para satisfacer las necesidades en alimento, recursos y energía, así como la superficie necesaria para absorber los residuos que producimos y añadiendo el impacto ambiental de nuestras infraestructuras. Debemos reducir nuestra huella ecológica, para no superar la capacidad de carga de la biosfera. Actualmente la huella ecológica por persona sostenible es de 1,8 hectáreas. Pero actualmente se calcula que el espacio consumido por persona es de 2,2 hectáreas. Vivimos a crédito, desde 1970 hasta 1996 la huella ecológica ha aumentado un $50 \%$. Lo más grave es que un ciudadano de Estados Unidos consume 9,6 hectáreas, un europeo 4,5. Esto es inviable, más cuando la huella ecológica de los ciudadanos de países como India o China crece rápidamente. Latouche (2009) propone un decrecimiento sereno basado en: reducir, reevaluar, reconceptualizar, relocalizar y reutilizar. Se manifiesta la necesidad de educar en una ciudadanía ecológica. La gravedad de la situación nos tiene que llevar a un compromiso con el planeta.

Vivimos sumidos en una ética laxa e indolora (LIPOVETSKY, 1994), propia de una sociedad hedonista de consumidores, que no de ciudadanos. Una sociedad que se caracteriza por la banalidad de los gestos (CRUZ, 1995) que trasforman la lucha contra el cambio climático en sustituir una bolsa de plástico por una de cartón, lo cual es apropiado pero no es suficiente. Una época marcada por el culto a la religión tecno-científica y un relativismo moral, según el cual nada es bueno, nada malo. Así no hay nada incorrecto en deforestar el amazonas. ¿Nada es bueno, nada es malo? Evidentemente sí. Debemos reaccionar desde un imperativo ético que nos obliga a responder desarrollando una solidaridad intra-generacional, con todos los seres humanos; y también inter-generacional, con las futuras generaciones. Un imperativo ético que cuestiona nuestro trato cruel con los animales y el medio natural. Si bien Platón afirmaba que el mundo es un ser vivo dotado de alma y de inteligencia, una entidad viva y visible que contiene a todas las demás entidades vivas relacionadas entre sí (citado en BLOOM, 2006), las religiones cristiana, judía y musulmana, han partido de la idea de que el hombre estaba hecho a imagen de Dios y que el mundo era su herencia, le pertenecía. Esta idea la retomaron científicos como Descartres en su llamado al dominio, control y explotación de la tierra. Ante esta realidad la Liga Internacional de los Derechos de los Animales proclamó la Declaración de derechos del animal, aprobada por la UNESCO y por la ONU (MOSTERÍN, 1998). La suposición de que los animales no tienen derechos y la ilusión de que nuestra forma de tratarlos no tiene significado moral es un claro ejemplo de crueldad y de barbarie occidentales (Schpenhauer, citado en BLOOM, 2006). Pero no podemos olvidar que estamos en un momento clave donde el imperativo ético se funde con el imperativo de supervivencia.

\section{La ecología ocupacional}

\section{Ando con cuidado sobre la piel de la madre tierra para no pisar las almas de las generaciones futuras que esperan su turno para vivir. Canto indígena.}

Santos (2005) propone una hermenéutica diatópica para completar nuestras creencias fuertes erróneas. Iwama (2006) contrasta nuestra cosmovisión occidental basada en la independencia, con la oriental basada en la interdependencia de los seres humanos, con los dioses y con la naturaleza. Mi trabajo con comunidades de refugiados guatemaltecos (SIMÓ ALGADO; ESTUARDO CARDONA, 2006) me permitió profundizar en la cosmovisión maya estudiando con un Ajgij, o sacerdote maya. Su misión es preservar el equilibrio entre el ser humano, la naturaleza y Dios. La pérdida de esta armonía origina la enfermedad. "La Tierra es mi madre; la Tierra es un ser vivo. Ella me alimenta, vivo gracias a ella. Vivimos gracias al agua, al viento, al fuego, a la lluvia. El hombre pertenece a la tierra. Si una persona le da la espalda a la naturaleza, caerá enferma sin esperanza". Cuando un ser humano nace está hermanado con un elemento de la naturaleza, llamado nagual, puede ser un jaguar o un quetzal, sus destinos están unidos (SIMÓ ALGADO, 2012). Casi todas las culturas indígenas reflejan la realidad 
sagrada de la vida. Podemos escuchar sus voces plenas de sabiduría:

Soy todas las fuerzas y los elementos con los que estoy en contacto. Soy el viento, los árboles, los pájaros y la oscuridad. (CURTIS, 1972),

"El sol, la luna, y los árboles son símbolos de mi continuidad" (PIGEM, 1994). Nuestras sociedades occidentales, basadas en los valores económicos impuestos por el capitalismo, han olvidado este carácter sagrado.

El genocidio ecológico se relaciona con el cultural. Davis (2001) expone como alrededor de 300 millones de personas pertenecen a culturas indígenas. No hay una mayor medida que refleje esta crisis cultural que la pérdida de lenguas. De las 10.000 que han existido, hoy 6.000 todavía se hablan, pero solo 600 lenguas son consideradas estables. Desde un punto de vista económico su pérdida parece superflua. Pero una lengua es un reflejo del espíritu humano, el filtro a través del cual el alma de cada cultura particular se relaciona con el mundo. En peligro se encuentra la expresión espiritual, intelectual y artística de la experiencia humana. Shiva (1994) nos alerta de la desaparición de las poblaciones indígenas justificada desde el mal llamado progreso. La destrucción que tiene un carácter más irreversible es la de los mecanismos culturales de las poblaciones indígenas, unos mecanismos que protegen tanto a la población misma como a su entorno natural. Cuando éstos desaparezcan, ¿quién nos enseñará a caminar sobre la Tierra con delicadeza?

Debemos reconsiderar cuál es en verdad la esencia del ser humano, pues el no reconocerla está ligada con la destrucción del medio natural. Somos seres bio-psico-sociales, con una esencia espiritual inmersos en un medio cultural y ecológico. La espiritualidad está ligada a la dimensión de conexión, con uno mismo (sentimientos, valores, visiones), con el resto de seres humanos (solidaridad intra e intergeneracional) y con la creación o medio natural. La ecopsicología ya mostró como la destrucción del medio ambiente afectaba a la psique humana. Somos seres dependientes, en especial durante la infancia, la senectud o la enfermedad, lo que nos hace volvernos a los demás, a través de los valores y las virtudes (MACINTYRE, 2001), igualmente dependientes del medio natural. Seres inter-dependientes, pero también capaces de palabra, de acción y de narración (RICOEUR, 2005), entre todas y todos podemos y debemos escribir una nueva narrativa para la Humanidad, basada en una sostenibilidad eco-social.

Sería un craso error pensar el problema ecológico como separado de la crisis social. Como dice Boff
(2000) la ecología es la relación del todo con el todo y el principal problema ecológico es la pobreza. Podemos pensar en los miles de personas, en especial comunidades indígenas, que son desarraigadas a la fuerza de sus comunidades ancestrales y condenadas a la miseria para facilitar la explotación de los recursos naturales de sus tierras (CASTILLO, 2011), o en cómo la agricultura industrial basada en semillas transgénicas está afectando al medio ambiente y empobreciendo a los agricultores (SHIVA, 2003, 2006). Este artículo no profundiza en el aspecto social, me limito a referir al lector a la excelente producción académica del grupo Metuia-Brasil, dedicado a la realización de investigaciones, a la educación y al desarrollo de intervenciones en el campo social que buscan la innovación por medio de nuevas metodologías participativas, dedicándose a enfrentar las problemáticas sociales contemporáneas (BARROS; LOPES; GALHEIGO, 2002).

Tampoco es posible separar la salud de la ecología. La salud es una experiencia de completo bienestar físico, psicológico, social (ORGANIZAÇÃO..., 1986, 2008). Podemos definir la salud desde una perspectiva ocupacional (WILCOCK, 1998) como: la ausencia de enfermedad, pero no necesariamente discapacidad; un equilibrio entre bienestar físico, mental y social, obtenido a través de ocupaciones significativas, valoradas social e individualmente; desarrollo del potencial personal; oportunidad de participación social y cohesión; e integración social, apoyo, justicia, todo como una parte en equilibrio con la ecología.

Es de destacar la pobre atención que los terapeutas ocupacionales hemos prestado al medio ambiente, más cuando la ocupación es el diálogo entre el ser humano (grupo o comunidad) y su medio. Por lo general, nos hemos quedado en el análisis de los aspectos físicos del medio, en especial de las barreras arquitectónicas, pero hemos mostrado una grave negligencia ante los condicionantes sociopolíticos como ecológicos. Esto nos inhabilita/ ba para ser verdaderos expertos sobre la ocupación humana. Wilcock $(1998,2006)$ sostiene que la ocupación humana ha sido la principal culpable de la degradación ecológica, y por tanto es necesario reconsiderarla urgentemente y efectuar los cambios que conduzcan a la rehabilitación ecológica. Debemos buscar la sostenibilidad ecológica. Do Rozario (1993) estableció una visión ecológica al sostener que debemos trabajar por una relación armoniosa de la gente con el medio ambiente, y hacerlo acercando a los individuos y a las comunidades hacia la salud, el bienestar y la sostenibilidad a través de la interacción, la ocupación y la acción sociopolítica. Esta declaración 
es coherente con la Declaración de Ottawa (1986) y Yakarta (1997) para la promoción de la salud y el modelo de sostenibilidad ecológica de la salud, entendido como la promoción de unas relaciones saludables entre seres humanos, otros organismos vivos, sus ecosistemas, hábitos y formas de vida.

Otra contribución es la de Persson y Erlandsson (2002) basada en el filósofo Skolimowsky, quien argumentó que el estilo de vida postindustrial implica un incremento del tempo y de la cantidad de las ocupaciones, la manipulación del tiempo, los organismos y del medio ambiente, y la reducción de sueño, descanso y juego, lo que impacta negativamente en nuestro bienestar y calidad de vida. Por el contrario, estamos atrapados en una perspectiva que enfatiza la competitividad y la eficacia de costes que es un producto del mercado occidental, la institución de poder de la sociedad postindustrial y de la ética de las máquinas. Sin embargo, si reflexionamos sobre nuestras elecciones ocupacionales, con el apoyo de la sabiduría antigua contenida en la biosfera, podemos usar nuestro tiempo basados en la calidad y no en la cantidad. Persson y Erlandsson (2002) definen el concepto de eco-pación ${ }^{2}$, como una elección ocupacional basada en una preocupación por el contexto ecológico a un ritmo que da espacio para la reflexión y la experiencia de sentido. Ciertamente la ocupación se inscribe en una dimensión simbólica, espacial (lo físico y lo geográfico) y temporal (lo histórico, lo subjetivo, lo rítmico y lo cíclico) (MÉNDEZ, 2011). La definición de eco-pación es próxima a mi definición de ocupación significativa, [...] el cruce de caminos ocupacional entre las necesidades, la potencialidad y el espíritu de la persona (grupo o comunidad). Porque expresamos nuestra espiritualidad a través de nuestras acciones (EGAN; DELAAT, 1994) y ya hemos visto la importancia de establecer una conexión con la propia creación para alcanzar el bienestar espiritual, entendido como una experiencia de plenitud. No en vano la naturaleza es una de las sendas reales de la espiritualidad apuntadas por Dürkheim (THIBEAULT, 2003).

Defino la ecología ocupacional como un doble movimiento de acción-reflexión, entendido como la toma de conciencia del genocidio ecológico al que nos enfrentamos que pone el peligro la Vida misma en la Tierra, momento de reflexión; que debe ser seguido por la toma de medidas proactivas para, a través de la ocupación humana, restablecer el equilibrio con el medio ambiente, momento de acción. Una acción consciente del ingente potencial terapéutico de la naturaleza, como han mostrado nuestras investigaciones (SIMÓ ALGADO, 2008, 2011).

Está definición está inspirada por el filósofo Mounier (2002) quien proponía una revolución personalista basada en los ciclos de acción y reflexión, que comparaba con los movimientos de sístole y diástole del corazón humano, una revolución de los valores y de las estructuras. La ecología ocupacional es coherente con el desarrollo sostenible y el decrecimiento sereno (LATOUCHE, 2009), ya que la ocupación humana es el medio para reciclar, relocalizar, reducir, y reutilizar. Asimismo con el principio de responsabilidad que nos plantea Jonas (1995), que enfatiza la importancia de la acción humana: obra de tal modo que los efectos de tu acción sean compatibles con la permanencia de una vida humana auténtica en la Tierra.

Se articula con la teoría del Renacimiento ocupacional (SIMÓ ALGADO, 2011), que desarrollaremos en el próximo artículo, así como con el principio de justicia ocupacional (TOWNSEND, 1993) que propone la promoción de un cambio social y económico que garantice el acceso a opciones significativas, ya que la ecología ocupacional implica un cambio en nuestros estilos vida así como crear alternativas al sistema capitalista. También lo hace con la perspectiva ocupacional de la salud (WILCOCK, 1998), ya que ésta habla del equilibrio con la ecología. Asimismo encuentra eco en una terapia ocupacional basada en los derechos humanos (GUAJARDO; SIMÓ ALGADO, 2010; GUAJARDO, 2002), ya que a los derechos políticos, de primera generación, le siguieron los sociales, de segunda generación, así como los del acceso al patrimonio común de la Humanidad y la sostenibilidad, los derechos humanos de tercera generación.

Como afirma Méndez (2011) las acciones del terapeuta ocupacional se centran en orientar a la persona para contribuir con su bienestar; este papel puede contribuir a disminuir la amenaza social y ecológica y el impacto en el medio ambiente como consecuencia del actuar humano. Podemos desarrollar una terapia ocupacional eco-social, cuyo principal objetivo es la co-creación de comunidades inclusivas y sostenibles, junto a las comunidades con las que tenemos el privilegio de trabajar, que defino como "aquel grupo humano que se reconoce interdependiente y en el que toda persona se siente y participa como ciudadano de pleno derecho, a pesar de cualquier problemática ocupacional, que se desarrolla en armonía con el medio natural asegurando las necesidades presentes sin comprometer las de las generaciones futuras para satisfacer las propias". 


\section{Conclusión}

El ser humano es parte del todo que nosotros llamamos universo, una parte limitada por el tiempo y el espacio. Se percibe a si mismo, sus pensamientos y sentimientos como algo separado del resto, lo cual constituye una especie de ilusión óptica de su conciencia. Para nosotros esta ilusión es como una prisión que restringe nuestros deseos y nuestros afectos a un puñado de personas de nuestro alrededor. Nuestra tarea debe consistir en liberarnos de esta prisión, y para ello debemos ampliar nuestro circulo de compasión hasta abrazar a todas las criaturas vivientes y la totalidad de la naturaleza en toda su belleza. Einstein

Los terapeutas ocupacionales no podemos seguir ignorando la importancia del medio ambiente si realmente nos queremos erigir como los expertos en la ocupación, ya que la ocupación es el diálogo entre el ser humano y su medio. Si queremos sobrevivir, este diálogo debe basarse en la reverencia y el respeto, el ser humano debe cuidar del santuario de la vida. Como afirma una oración india "los humanos no son ni mejores ni peores que una piedra, pero nuestra misión es cantar, cantar el Mundo, cantar la Belleza" (fuente desconocida).

Debemos profundizar en nuestro conocimiento de la actual crisis ecológica, de cómo realidades como la lluvia ácida, la deforestación, el agujero de ozono, el cambio climático o la contaminación afectan a la salud y al bienestar del ser humano. Es preciso comprender sus consecuencias, como la existencia de migrantes medioambientales, definidos como toda persona que abandona su territorio de residencia habitual debido a los impactos ambientales, ya se muevan dentro de un mismo Estado o atraviesen fronteras (CASTILLO, 2011). El Alto Comissário das Naçốes Unidas Para Refugiados (2012) estima que 24 millones de personas han huido de sus hogares a causa de inundaciones, hambrunas u otros desastres medioambientales. Su cálculo para 2050 es de 150 millones de emigrantes ambientales.

La ocupación humana ha jugado un rol clave en la génesis de esta crisis medioambiental y debe jugarlo en su restauración. Una crisis enraizada en nuestra fe ciega en el progreso y en un modelo económico enajenado que pretende un crecimiento ilimitado en un mundo con recursos limitados. Un sistema que pone al hombre al servicio de la economía, que convierte al bios politikos en un triste animal laborans y en un homo consumens cuyo estilo de vida se traducen en una huella ecológica insostenible.
Como dice Bohm (2001) uno de los grandes problemas actuales es que tendemos a ser repetitivos cuando necesitamos ser creativos. La terapia ocupacional presume de esta creatividad, es tiempo, pues, de materializarla sobre el lienzo de la vida, desarrollando una terapia ocupacional eco-social que contribuya a la co-creación de comunidades inclusivas y sostenibles. El concepto de ecología ocupacional nos puede ayudar, a entender mejor esta imperiosa necesidad de reflexión/acción ante la grave crisis medioambiental que confrontamos, que no podemos separar la crisis social. La ecología ocupacional es una idea fuerza, más allá de un concepto ligado a una definición, que será vano y estéril, si a esta reflexión no le siguen acciones decididas de restauración del medio natural, como las del movimiento Chipko (BIGAS, 1992), que significa abrazo, de mujeres indias que se abrazaban literalmente a los árboles para evitar su tala. Acciones que debemos desarrollar junto con personas y comunidades excluidas del medio social, como el desarrollo de proyectos que integren la rehabilitación ecológica con la inclusión laboral de personas en situación de exclusión social, como el proyecto $\mathrm{SHES}^{3}$, coordinado por el primer autor en Vic (Barcelona), en el que se han rehabilitado cuatro parajes naturales de alto valor ecológico al tiempo que se generaban 10 contratos de trabajo; o el proyecto liderado por Gloria Silva en Santiago de Chile, basado en el reciclaje de materiales como el vidrio o el cartón desde un centro de personas con trastornos mentales. Acciones como Green OT ${ }^{4}$ que estudia una práctica sostenible de la Terapia Ocupacional. En el siguiente artículo profundizaremos en acciones, actitudes, y cambios de hábitos relacionados con la ecología ocupacional.

Morin (1993) plantea como en 1492 fue inaugurada la Edad planetaria, asimismo afirma que en 1945 con la bomba de Hiroshima entramos en la Edad Damoclea, refiriéndose a la espada de Damocles, ya que desde entonces el ser humano puede provocar su propia extinción. No en vano según Beck (1998) vivimos en la sociedad del riego. Morin nos llama a civilizar la civilización para reconocer a la Tierra como nuestra Patria común. Estamos en un momento clave, la disyuntiva es civilización o barbarie.

La propia naturaleza es nuestra maestra y nos enseña que tras el crudo invierno llega la primavera, la radiante luz del alba sigue a la oscura noche. Todos estamos llamados a protagonizar esta nueva primavera de la Humanidad, este Renacimiento. Dos Santos empieza un poema con estas palabras: "sembremos, madre, sembremos, en las estrellas, en la mar". Es tiempo de sembrar una nueva sociedad 
basada en los valores de la solidaridad, la justicia y la sostenibilidad; una sociedad basada en los derechos humanos y respetuosa con los de los animales. Es tiempo de recordar nuestra maravillosa capacidad humana de palabra, de acción, y de narración para escribir una nueva narrativa para la Humanidad.

No debemos hacerlo desde una sensación de sacrificio, sino de celebración. Debemos celebrar el milagro de la vida y la creación. Cuando nos sumergimos en el medio natural y contemplamos su grandiosidad y belleza, somos conscientes de que es un tesoro que debemos preservar, un tesoro creado por la evolución durante millones de ańos. Cuando pensamos en la probabilidad infinita que supone el origen de la vida en la Tierra, el surgimiento de la vida orgánica a partir de la inorgánica, y de la vida humana a partir de la orgánica, no podemos dejar de sentir la vida es un milagro (ARENDT, 1997). Sembremos pues, reforestemos de árboles y de valores este hermoso mundo, conscientes de que un día se lo tenemos que devolver a sus legítimos propietarios, que no son otros que las próximas generaciones que esperan su turno para vivir.

\section{Referencias}

ALTO COMISSÁRIO DAS NAÇÓES UNIDAS PARA REFUGIADOS - ACNUR. Más de 150 millones de personas serán refugiados ambientales en 2050. Publicado el 20 de enero de 2012 y descargado el 25 de enero de 2012. Disponível em: <http://www.acnur.org/index.php?id_pag=6478>.

ARENDT, H. ¿Qué es la política? Barcelona: Paidós. 1997. BARROS, D. D.; LOPES, R. E.; GALHEIGO, S. M. Projeto Metuia - terapia ocupacional no campo social. O Mundo da Saúde, v. 26, n. 3, p. 365-369, 2002.

BAUMAN, Z. Vidas desperdiciadas: La modernidad y sus parias. Barcelona: Paidós. 2005.

BECK, U. La sociedad del riesgo. Barcelona: Paidós, 1998. BECK, U.; BECK-GERNSHEIM, E. La individualización. Barcelona: Paidós, 2003.

BIGAS, J. Vivir ligeramente sobre la tierra. Barcelona: Integral, 1992.

BLOOM, S. Espiritu animal. Barcelona: Blume, 2006.

BOFF, L. La dignidad de la tierra: Ecología, mundialización, espiritualidad. La emergencia de un nuevo paradigma. Madrid: Trotta, 2000.

BOFF, L. Ética planetaria desde el gran Sur. Madrid: Trotta, 2001.

BOHM, D. Sobre la creatividad. Barcelona: Kairós, 2001.

CARSON, R. Una primavera silenciosa. Madrid: Crítica, 2010.

CASTILLO, J. Migraciones ambientales. Barcelona: Virus Editorial, 2011.
COMISSÃO MUNDIAL SOBRE O MEIO AMBIENTE E O DESENVOLVIMENTO - CMMAD. Nuestro futuro común. Madrid: Alianza, 1998

CURTIS, E. The North American Indians. Hong Kong: Aperture, 1972.

CRUZ, M. Elementos para una ontología de la acción. In: ARENDT, H. De la historia a la acción. Barcelona: Paidós, 1995. p. 9-28.

DAVIS, W. Light at the edge of the world. Vancouver: Douglas\&McIntyre, 2001

EGAN, M.; DELAAT, D. Considering spirituality in occupational therapy practice, 1994. Canadian Journal Occupational Therapy, v. 61, n. 2, p. 95-101, 1994.

EHRLICH, P.; EHLRICH, A. La explosión demográfica: El principal problema ecológico. Barcelona: Salvat, 1993.

GARCÍA, E. Medio ambiente y sociedad: La civilización industrial y los límites del planeta. Madrid: Alianza, 2004. GUAJARDO, A. Salud Mental y Reparación: Políticas de Estado. In: INTERNACIONAL PARA LA REHABILITACIÓN DE AFECTADOS POR LA TORTURA - IRCT. Salud Mental y Derechos Humanos en el Cono Sur. Buenos Aires: Editorial Polemos, 2002. p. 321-332.

GUAJARDO, A. Prólogo. In: TRUJILLO ROJAS, A. et al. Ocupación: sentido, realización y libertad. Bogotá: Universidad Central de Colombia, 2011. p. 13-20.

GUAJARDO, A.; SIMÓ ALGADO, S. Hacia una terapia ocupacional basada en los derechos humanos. TOG, v. 7 , n. 12, p. 25, 2010. Disponível em: <http://www.revistatog. com/num12/pdfs/maestros.pdf $>$. Acesso em: jan. 2012.

IWAMA, M. Ubicación en el contexto: cultura, inclusión y terapia ocupacional. In: KRONENBERG, F.; SIMÓ ALGADO, S.; POLLARD, N. Terapia Ocupacional sin Fronteras: Aprendiendo del espíritu de supervivientes. Madrid: Editorial Médica Panamericana, 2006. p. 127-141.

JONAS, H. El principio de responsabilidad: ensayo de una ética para la civilización tecnológica. Barcelona: Herder, 1995.

KANT, I. Lo bello y lo sublime. Madrid: Espasa Calpe, 1946. LATOUCHE, S. Petit tractat sobre el decreixement serè. Valencia: Tres i Quatre, 2009.

LIPOVETSKY, G. El crepúsculo del deber. Barcelona: Anagrama, 1994.

LOVELOCK, J. Gaia, una nueva visión de la vida sobre la Tierra. Barcelona: Orbis. 1985.

MACINTYRE, A. Animales racionales y dependientes. Barcelona: Paidós Ibérica, 2001.

MEADOWS, D. Los limites del crecimiento: informe al Club de Roma. Ciudad de Méjico: fondo de Cultura Económica, 1972.

MÉNDEZ, M. J. A. La ocupación como proceso ecológico. In: TRUJILLO ROJAS, A. et al. Ocupación: sentido, realización y libertad. Bogotá: Universidad Central de Colombia, 2011. p. 130-150.

MORIN, E. Tierra Patria. Barcelona: Paidós, 1993. 
MOSTERÍN, J. ¡Vivan los animales!. Madrid: Debate, 1998.

MOUNIER, E. El personalismo: Antología esencial. Salamanca: Ediciones Sígueme, 2002.

ORGANIZACIÓN MUNDIAL DE LA SALUD - OMS. Carta de Ottawa. Ginebra: OMS, 1986.

ORGANIZACIÓN MUNDIAL DE LA SALUD - OMS. Declaración de Yakarta. 2008. Disponível em: <http:// www.who.int/hpr/NPH/docs/jakarta_declaration_sp.pdf >. PERSSON, D.; ERLANDSSON, L. K. Time to reevaluate the machine society: post-industrial ethics from an occupational perspective. Journal of Occupational Science, v. 9, n. 2, p. 93-99, 2002. http://dx.doi.org/10.1080/14 427591.2002 .9686497

PIGEM, J. Nueva conciencia. Barcelona: Integral, 1994. RAND, H. Hunderwasser. Madrid: Taschen, 2007.

RENDUELES, G. Viejos y nuevos locos. In: CASTEL, R. et al. Pensar y resistir: La sociología crítica después de Foucault. Madrid: Círculo de Bellas Artes, 2006.

RUSSELL, B. ¿Tiene futuro el hombre? Madrid: Aguilar, 1962

RICOEUR, P. Caminos del reconocimiento. Madrid: Editorial Trotta, 2005.

ROZARIO, L. Purpose, place, pride and productivity: the unique personal and societal contribution of occupation and occupational therapy. In: CONFERENCIA DE LA ASOCIACIÓN AUSTRALIANA DE TERAPIA OCUPACIONAL,17., 1993, Darwin. Actas... Darwin, 1993.

SANTOS, B. El milenio huérfano. Ensayos para una nueva cultura política. Madrid: Editorial Trotta, 2005. SIMÓ ALGADO, S.; ESTUARDO CARDONA, C. El regreso del hombre de maíz: un proyecto de intervención con una comunidad maya de retornados guatemaltecos.
In: KRONENBERG, F.; SIMÓ ALGADO, S.; POLLARD, N. Terapia Ocupacional sin Fronteras: Aprendiendo del espíritu de supervivientes. Madrid: Editorial Médica Panamericana, 2006. p. 339-354.

SIMÓ ALGADO, S. Una universidad donde confluyen la educación, la investigación y la ciudadaní. Universidad de Vic, 2008. Disponível em: <http://www.recercat.net/ bitstream/handle/2072/5326/PROGRAMA\%20DE\%20 DOCTORADO\%20FINALcat.pdf? sequence $=1>$.

SIMÓ ALGADO, S. La palabra y la acción: lucha contra la pobreza, ciudadanía y salud a partir de nuevas praxis universitarias. 2011. $344 \mathrm{f}$. Tese (Doutorado em Educação)-Universidad de Vic, Vic, 2011. Disponível em: <http://tdx.cat/bitstream/handle/10803/9325/ PALABRAACCION.pdf?sequence $=1>$.

SIMÓ ALGADO, S. Cuadernos de viaje. 2012. En edición. SHIVA, V. El vínculo sagrado con la tierra. En: PIGEM, J. Nueva conciencia. Barcelona: Integral, 1994.

SHIVA, V. Cosecha robada. Barcelona: Paidós. 2003.

SHIVA, V. Manifiesto para una democracia de la tierra. Barcelona: Paidós, 2006.

SOLANA, A. Ciudades y contaminación. Barcelona: Lunwerg, 2010.

THIBEAULT, R. Experimental and philosophical considerations on occupation and the genesis of meaning and resilience. In: McCOLL, M. A. (Ed.). Spirituality and occupational therapy. Ottawa: CAOT, 2003. p. 83-95. TOWNSEND, E. Occupational therapy's social vision. Canadian Journal of Occupational Therapy, v. 60, n. 4, p. 174-184, 1993.

WILCOCK, A. An occupational perspective of health. Thorofare: Slack Incorporated, 1998.

WILCOCK, A. An occupational perspective of health. 2. ed. Thorofare: Slack Incorporated, 2006.

\section{Notas}

${ }^{1}$ El texto es fruto de las reflexiones de la tesis doctoral La palabra y la acción, (ver http://www.tesisenred.net/bitstream/ handle/10803/9325/PALABRAACCION.pdf?sequence=1) así como de los proyectos de terapia ocupacional eco-social liderados por el autor.

2 Traducción del concepto eco-pation, realizada por el autor.

${ }^{3}$ Ver www.sos-ecosocial.org

${ }^{4}$ Ver http://sustainablehealthcare.org.uk/ot-susnet 